\title{
El diálogo interjurisdiccional entre tribunales extranjeros e internos como nueva construcción de las decisiones judiciales
}

The Inter-jurisdictional Dialogue between Foreign and National Courts as New Construction of Judicial Decisions doctor en Derecho Constitucional (UBA). Postgrado de la Universidad de Harvard (USA) y de las universidades de San Francisco (USA) y George Washington University (USA). Profesor de Derecho Constitucional y Procesal Constitucional de la UBA, de la Universidad de Rosario (UNR) y de la Universidad de Lomas de Zamora (UNLZ). 


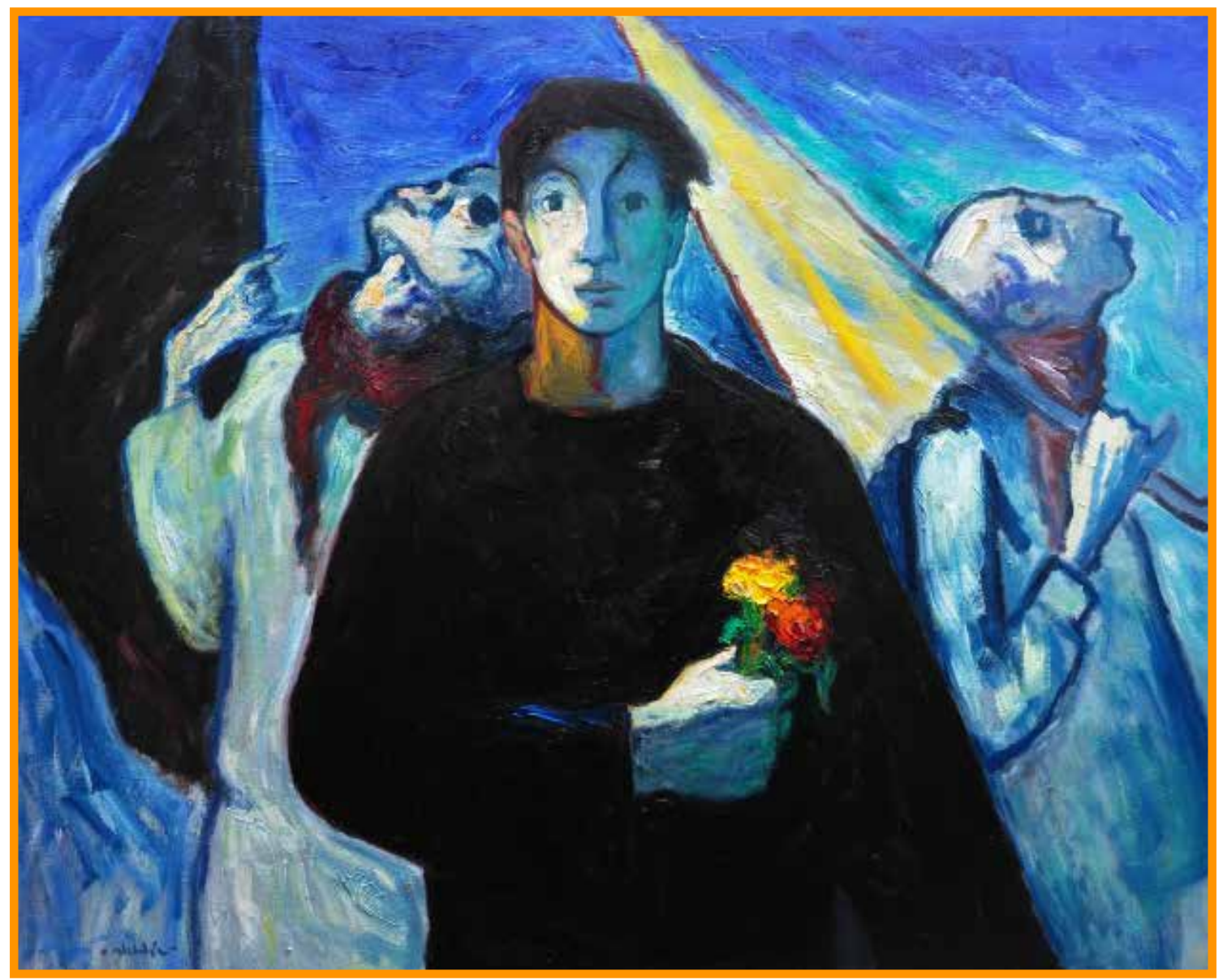

Reflexión. Óleo sobre tela $(120$ x $90 \mathrm{~cm})$. 


\section{RESUMEN}

En este artículo, el autor expone en lo esencial la relación que en torno del Derecho mantienen los tribunales nacionales, en particular el de Argentina, con organismos de justicia internacionales, e incluso con los de otros países, para orientar y configurar determinadas decisiones judiciales, sobre todo aquellas relacionadas con el respeto a los convenios internacionales que tienen que ver con el respeto de los derechos humanos.

Palabras clave: Derecho Internacional, Derecho Interno, derechos humanos, diálogo interjurisdiccional.

\section{ABSTRACT}

In this article, the author presents essentially the relationship about the national law courts, particularly in Argentina, with international justice agencies, and even with other countries, to guide and set certain judicial decisions, especially those related to the respect of international agreements that have to do with respect for human rights.

Key words: International Law, National Law, human rights, inter-jurisdictional dialogue. 



\section{INTRODUCCIÓN}

La lucha del constitucionalismo por la limitación del poder y el reconocimiento y vigencia de los derechos aspira - en su largo derrotero desde el siglo XVII — a la integración de un Derecho Universal o ius comune universalis que se funda en los valores de la dignidad humana a través de su denominación moderna de derechos humanos que recuerda al derecho natural, como magistralmente expusiera Giuseppe de Vergottini. ${ }^{1}$

Así, los derechos han sido el motor fundamental de las luchas de la humanidad por un orden más justo. El Derecho Constitucional ha estado y sigue estando motivado por la idea de que solo el Estado de Derecho, es decir, solo un Estado organizado con sujeción a la ley y fundado en la soberanía popular, puede garantizar la libertad y los derechos.

Esta aspiración, que sufrió duros embates por los regímenes totalitarios en nombre de la soberanía estatal absoluta, generó — luego de la catástrofe de la Segunda Gran Guerra — un orden caracterizado por la internacionalización de los derechos en los ámbitos regionales en América la Organización de Estados Americanos (OEA), y en el universal, las Naciones Unidas (UN) —, lo que provocó la apertura y universalización del Derecho Constitucional y su integración con el Derecho Internacional, para dar nacimiento al denominado Derecho de los Derechos Humanos.

Esta nueva disciplina nos ha traído diversas técnicas normativas, ya sea de declaración, de interpretación e incluso de constitucionalización de los tratados internacionales de derechos humanos, creando un espacio común de los derechos. Se ha configurado así lo que ha dado en llamarse —siguiendo a Cappelletti- la dimensión supranacional del derecho del proceso y de la justicia, con la evidente intención de que el respeto de las libertades humanas logre un nivel de meta nacional y uniforme. ${ }^{2}$

Giuseppe de Vergottini. Más allá del diálogo entre tribunales. Madrid: Civitas, 2010.

Cfr. Juan Carlos Hitters y Óscar Fappiano. Derecho Internacional de los Derechos Humanos. Buenos Aires: Ediar, 2006. 
Los tribunales nacionales argentinos - a partir de la ratificación legislativa de la Convención Americana de Derechos Humanos (CADH), acaecida en 1984- poseen doble fuente normativa para realizar las interpretaciones judiciales de los derechos, generándose además la necesidad de adecuar la jurisprudencia nacional a la jurisprudencia internacional emanada de los órganos creados por la $\mathrm{CADH}$ para la protección de los derechos que ella enumera: la Corte IDH y la Comisión IDH.

Sin embargo, es dable aclarar, de inicio, que el hecho de que un tribunal haga referencia o cite a la jurisprudencia de otro tribunal no constituye de por sí un diálogo interjurisdiccional, sino que esto solamente ocurre cuando el tribunal receptor de la jurisprudencia la analiza razonadamente y explica y aplica su significado y alcance en la decisión del caso.

La confrontación con sus propios antecedentes que debe hacer el tribunal que recibe la jurisprudencia a través de un proceso de argumentación es la que va a permitir el verdadero diálogo jurisprudencial. De esta forma, la jurisprudencia recibida produce una fertilización en la jurisprudencia receptora. ${ }^{3}$

\section{EL MONÓLOGO REFERENCIAL CON LA CORTE SUPREMA DE LOS ESTADOS UNIDOS EN EL EJERCICIO DEL CONTROL DE CONSTITUCIONALIDAD}

Bueno es recordar, previamente, dos características del sistema de gobierno argentino: su carácter federal, donde cada Estado parte o provincia dicta su propia Constitución que debe garantizar su administración de justicia pero que la organiza en forma autónoma, y las particulares características de su sistema de control de constitucionalidad vigente desde los albores de la organización nacional, que es judicial y difuso, a similitud del modelo norteamericano, nacido popularmente a partir del famoso leading case Marbury vs. Madison, fallado por la Corte Suprema de los Estados Unidos de Norteamérica en $1803 .{ }^{4}$

El control de constitucionalidad, mecanismo institucional que tiene por objeto garantizar el principio de supremacía de la Constitución frente al resto de las normas internas, se presenta en el mundo occidental a través de dos grandes modelos, que muchos países en América han combinado: el modelo concentrado y el difuso.

En el modelo concentrado, típicamente europeo, la revisión es hecha exclusivamente por un Tribunal Constitucional diseñado para tales fines, y la declaración de inconstitucionalidad produce efectos erga omnes, con la consiguiente anulación de la norma cuestionada. En el

Cfr. Carlos Ayala Corao. "Discurso de incorporación como individuo de número de la Academia de Ciencias Políticas y Sociales de Venezuela". Caracas, Venezuela: Paraninfo del Palacio de las Academias, 8 de marzo de 2012.

4 Jorge Alejandro Amaya. Marbury vs. Madison. Sobre el origen del control de constitucionalidad. Bogotá, Colombia: Ediciones Nueva Jurídica, 2012. 
difuso, corresponde a todos los jueces, sin distinción de categorías o jurisdicciones, llevar a cabo el control de constitucionalidad, sin perjuicio de llegar a la CSJN como tribunal último por vía de un recurso extraordinario, ya que es ella quien debe cumplir con el rol institucional de ser custodio de la supremacía de la Norma Fundamental. La sentencia de inconstitucionalidad solo implica no aplicar la norma en el caso resuelto; el efecto es limitado, restringido o interpartes, dejando subsistente la vigencia de la norma fuera de ese caso.

Por consiguiente, en Argentina, igual que en los Estados Unidos, todos los jueces de cualquier jurisdicción y competencia son jueces constitucionales, es decir, poseen la facultad de dejar sin validez, pero con efecto para el caso concreto, cualquier norma de cualquier jerarquía, en la medida que la encuentren repugnante frente a la Constitución Nacional.

Otra característica interesante referida al control de constitucionalidad en el marco de análisis es que, al contrario del modelo norteamericano, en mi país no rige la doctrina del precedente obligatorio o stare decisis, ya que no existe norma legal ni costumbre pacífica que establezca la obligación de los tribunales inferiores de acatar los fallos de la Corte Suprema de Justicia, más allá que los mismos son seguidos habitualmente en razón del valor moral de los mismos, tratándose la Corte Suprema de Justicia del máximo intérprete de la Constitución Federal. ${ }^{5}$

En el caso de la CSJN Argentina - como anticipé-, he denominado a su proceso de evolución en el intercambio dialogal con otros tribunales: "Del monólogo referencial del control de constitucionalidad al diálogo bidireccional del control de convencionalidad". Trataré de fundamentar el contenido de este título.

Desde su instalación en el año 1863, del cual se cumplen en estos días 150 años, el máximo tribunal de mi país se sintió obligado — como forma de fundamentar sus fallos-a hacer referencia argumentativa directa a los fallos de la Corte Suprema de Justicia de los Estados Unidos, en razón de la similitud de los modelos constitucionales, ya que, como bien dijo el principal redactor de la Constitución de 1853, el texto constitucional argentino había sido vaciado en el modelo norteamericano. ${ }^{6}$

La Corte, por muchos años, y aún hoy, pero en forma muy atenuada, invocó la jurisprudencia de la Corte Norteamericana, aunque más que una situación dialogal en este caso podríamos hablar de una situación de monólogo referencial, ya que esta relación se daba exclusivamente en una sola dirección y sin efectuar — la mayoría de las veces - un proceso razonado y profundo de la jurisprudencia del tribunal emisor, y más bien a través de la descripción breve del caso extranjero aplicable al caso argentino, en razón de la similitud del modelo constitucional.

Ídem. Control de Constitucionalidad. Buenos Aires: Astrea, 2012.

6 El principal redactor de la Constitución Argentina de 1853 fue Benjamín Gorostiaga. 
Desde esta situación de monólogo unilateral o referencial hasta la actualidad, Argentina ha recorrido un largo y fructífero camino en lo que hace a la incorporación de normas internacionales a su Derecho Interno y al consecuente diálogo interjurisdiccional con tribunales extranjeros.

III. EL PRINCIPIO DE SUPREMACÍA CONSTITUCIONAL Y SUS CAMBIOS. INCORPORACIÓN DE LA REPUBLICA ARGENTINA AL SISTEMA INTERAMERICANO: EL RECONOCIMIENTO DE LA COMPETENCIA DE LA CORTE IDH

Resulta necesario, para poder analizar cómo el Derecho Internacional comenzó a insertarse dentro de nuestro Derecho Interno, realizar un análisis jurisprudencial de las distintas posturas que a lo largo del tiempo nuestra CSJN fue adoptando.

El principio de supremacía constitucional en mi país hasta la reforma constitucional de 1994 estaba definido, principalmente, por los artículos 31 y 27 de la Constitución, que establecían la prioridad del Derecho Federal, constituido por la Constitución, las leyes federales y los tratados con potencias extranjeras, sobre el Derecho Local. Este contexto del Derecho Federal era considerado como "la ley Suprema de la Nación". Aplicando una teoría dualista, la CSJN tenía establecido desde 1947 en el caso "Merck Química” que el Derecho Interno se priorizaba sobre el Derecho Internacional en épocas de guerra y, viceversa, en épocas de paz.

La CADH, conocida popularmente como Pacto de San José de Costa Rica, junto con los órganos que ella impetra como protectores del sistema interamericano: la Comisión y la Corte, fue ratificada legislativamente por Argentina en marzo de 1984, ${ }^{7}$ pasando a integrar, de acuerdo a lo establecido en el artículo 31 de la Constitución Federal, la Ley Suprema de la Nación junto con la Constitución y las leyes federales y quedando sujeta a la interpretación que el máximo tribunal interno del país tenía establecido en torno a la jerarquía del Derecho Internacional. La Argentina reconoció — por el art. 2 de la ley ratificatoria - la competencia de la Comisión IDH por tiempo indefinido y de la Corte IDH sobre los casos relativos a la interpretación o aplicación de la CADH.

El primer indicio en la priorización definitiva del Derecho Internacional sobre el Interno se da en 1992, cuando la CSJN, en oportunidad de expedirse en el caso Ekmekdjian c. Sofovich, ${ }^{8}$ falló: "Que la interpretación de la $\mathrm{CADH}$ debe, además, guiarse por la jurisprudencia de la Corte Interamericana de Derechos Humanos". En este fallo, además, reconoció la supremacía legal de los tratados por sobre las leyes nacionales.

Ley $\mathrm{N}^{\circ} 23.054$.

8 CSJN en Ekmekdjian c. Sofovich. Sentencia del 7 de julio de 1992, considerando $N^{\circ} 21$. 
Dos años más tarde, en 1994, al reformarse la Constitución Federal, es cuando la CADH obtiene su certificado de mayoría o un salto cualitativo en su normatividad constitucional y en la de los órganos que ella impetra como protectores del sistema interamericano: la Comisión y la Corte.

Por dicha reforma, y conforme al art. 75 inciso 22 de la Constitución Federal, la CADH, y por consiguiente todo el sistema interamericano que ella organiza, adquiere — junto con otros diez tratados de derechos humanos - jerarquía constitucional.

Es decir que hoy el principio de supremacía constitucional en Argentina se integra en su cúspide por una doble fuente (interna e internacional): la Constitución Federal y los tratados de derechos humanos que recibieron jerarquía constitucional con la reforma constitucional, o aquellos que el Poder Legislativo le otorgó u otorgue en el futuro dicha jerarquía a través del procedimiento legislativo de ratificación con mayoría calificada. Esta doble fuente que integra la supremacía constitucional argentina se denomina bloque de constitucionalidad federal. ${ }^{9}$

Por debajo del bloque todo es Derecho infraconstitucional, dejando aclarado que el Derecho Internacional se prioriza sobre el Derecho Interno en atención a lo dispuesto por la propia Constitución. ${ }^{10}$

\section{EL DIÁLOGO INTERJURISDICCIONAL CON LA CORTE IDH. SUS DISTINTAS INTENSIDADES}

¿Cuál ha sido la evolución de la CSJN Argentina en el diálogo interjurisdiccional luego de la relación histórica con la Corte Suprema Norteamericana, considerando que desde 1994 posee jerarquía constitucional la $\mathrm{CADH}$ y por consiguiente las decisiones de la Corte IDH en su carácter de máximo intérprete de los derechos enumerados en la Convención?

El dialogo entre la Corte IDH y la CSJN comenzó progresivamente desde los años noventa, ${ }^{11} \mathrm{y}$ si bien hoy sus fallos y jurisprudencia tienen efecto vinculante para los tribunales argentinos, teniendo estos la obligación de ejercer un control de convencionalidad entre

\footnotetext{
9 Cfr. Germán Bidart Campos. Tratado elemental de Derecho Constitucional Argentino. Tomo I-A. Buenos Aires: Ediar, 2006.

10 Artículo 75, inciso 22 de la Constitución Nacional Argentina.

11 En el ámbito de la jurisdicción contenciosa ejercida por la Corte desde su instalación en 1979 hasta 2011, ha dictado un total de 238 sentencias de fondo, excepciones preliminares, reparaciones, costas e interpretación. El 73,5\% $(175)$ de esas sentencias han sido dictadas entre el año 2000 y el 2011. Salvo pocas excepciones, en prácticamente todas las sentencias de fondo la CIDH ha encontrado la violación de al menos uno de los derechos reconocidos en la Convención Americana. La jurisprudencia de la Corte sobre la interpretación de la Convención se complementa con las resoluciones sobre Medidas Provisionales dictadas hasta el 2011 en más de 110 asuntos (cada asunto cuenta normalmente con varias resoluciones) y con 296 resoluciones sobre cumplimento de las sentencias dictadas entre 2001 y 2011, así como las 20 Opiniones Consultivas dictadas desde 1982.
} 
el Derecho Interno y los derechos consagrados en la Convención Americana a la luz de la interpretación que de estos ha hecho la Corte, incluso de oficio, es decir, sin necesidad de que exista petición de parte, el proceso de reconocimiento y aceptación no ha sido fácil, ya que la justicia doméstica muchas veces se ha resistido a la internacional debido a una diversidad de factores vinculados con la falta de información, incomprensión, factores psicológicos y habitualmente ideológicos, etc. ${ }^{12}$

\section{LA CUESTIÓN DE LA OBLIGATORIEDAD DE LOS FALLOS DE LA CORTE $\mathrm{IDH}$}

La Corte IDH ha dejado en claro desde siempre que, en principio, no se ocupa en sí de las cuestiones domésticas sino que su tarea es la de inspeccionar si los países han violado o no las convenciones sujetas a su competencia, por lo cual ella no configura una cuarta instancia de apelación.

Por ello ha establecido en el caso Acevedo Jaramillo y otros v. Perú que una sentencia con carácter de cosa juzgada de los jueces domésticos “...tiene que ser necesariamente cumplida debido a que en ella se adopta una decisión de forma definitiva, otorgando certeza sobre el derecho o controversia discutida en el caso concreto, y tiene como uno de sus efectos la obligatoriedad. Ante este tribunal [agregó], eventualmente puede discutirse la autoridad de cosa juzgada de una decisión cuando esta afecta derechos de individuos protegidos por la convención y se demuestra que existe una causal de cuestionamiento de la cosa juzgada"13 y que solo circunstancias excepcionales pueden conducir a que el cuerpo supranacional “... deba ocuparse de examinar los respectivos procesos internos". ${ }^{14}$

Como vemos, esta doctrina legal tolera indirectamente la fiscalización de la actividad jurisdiccional doméstica y ha sido recibida por la Corte Suprema de la Nación Argentina con cierta cautela y con algunas idas y vueltas, aunque en los últimos tiempos ha sido acatada totalmente.

Una vez sancionada la reforma de 1994, la CSJN sostuvo en el caso Giroldi que "la jurisprudencia de los tribunales internacionales debe servir de guía para la interpretación de los preceptos convencionales en la medida en que el Estado Argentino reconoció la competencia de la Corte Interamericana de Derecho Humanos" ${ }^{15}$

12 Cfr. Néstor P. Sagües. Derecho Procesal Constitucional. Logros y obstáculos. Buenos Aires: Ad-Hoc, 2006.

13 Corte IDH, caso Acevedo Jaramillo y otros vs. Perú. Sentencia de 7 de febrero de 2006, Serie C No. 144, párr.167.

14 Corte IDH, Caso de la Masacre de Mapiripán vs. Colombia. Sentencia de 15 de septiembre de 2005, Serie C No. 13, párr. 198; Corte IDH, Caso Palamara Iribarne vs. Chile. Sentencia de 22 de noviembre de 2005, Serie C No. 135, párr. 121.

15 CSJN. Sentencia del 7 de abril de 1995. 
Llegado el año 1998, en oportunidad de pronunciarse en el caso "Acosta", ${ }^{16}$ la CSJN denota un franco retroceso en el proceso de reconocimiento del carácter vinculante de los fallos de la Corte IDH, cuando sostiene que la jurisprudencia internacional no podrá afectar la cosa juzgada a nivel interno.

Argentina fue condenada por primera vez por la Corte IDH en el año 2002 en el caso Cantos, por violentar los artículos 1.1, 8 y 25 de la Convención Americana sobre Derechos Humanos, al perjudicar el acceso a la justicia del reclamante. ${ }^{17}$ Ese tribunal mandó a la Argentina fijar nuevamente de manera razonable los gastos de un pleito por considerar que los determinados con anterioridad implicaban limitaciones económicas para el acceso a la justicia.

En dicho asunto, la CSJN no dio total acatamiento al decisorio referido invocando razones de "Derecho Interno". Dijo, por ejemplo, que la reducción de los emolumentos de los peritos oficiales que no habían participado en el juicio internacional afectaba el derecho de defensa. Sin embargo, la minoría entendió que el fallo debía respetarse en su totalidad por ser el mismo vinculante.

Luego, en el que fuera conocido como caso Bulacio, ${ }^{18}$ en el año 2003, la Corte IDH condenó nuevamente a la Argentina por violar los artículos 4, 7, 8, 25 y 1.1 de la Convención, en esta oportunidad por la muerte de un joven por parte de la policía. Dispuso allí que se investigue y se sancione a los responsables y que sean indemnizados los familiares. ${ }^{19}$

La CSJN —en un interesantísimo decisorio y por entonces con una nueva integracióncambió de criterio y acató totalmente la sentencia, ${ }^{20}$ a tal punto que dejó sin efecto un fallo local que había decretado la prescripción de la acción penal a favor del imputado (comisario Espósito), disponiendo que se juzgue nuevamente al mismo. ${ }^{21}$

Vemos en Espósito (Bulacio) un avance en la jurisprudencia interna. En efecto, la CSJN sostuvo por mayoría que “... la decisión de la Corte IDH... resulta de cumplimiento obligatorio para el Estado Argentino (art. 68.1, CADH), por lo cual también esta Corte, en principio,

16 CSJN. Sentencia del 28 de diciembre de 1998

17 Corte IDH, caso Cantos. Pronunciamiento del 28 de noviembre de 2002.

18 Corte Suprema de la Nación Argentina, Expte. 1307/2003. Decisorio del 21 de agosto de 2003.

19 Finalmente, y a fin de dar cumplimiento con la sentencia interamericana, el Poder Ejecutivo dispuso por un decreto que por intermedio de la Secretaría de Derechos Humanos del Ministerio de Justicia se llevarían a cabo las actuaciones pertinentes para dar cumplimiento a las sentencias. Decreto 1313 del 11 de agosto de 2008.

20 Corte Suprema de la Nación Argentina, Espósito, Miguel Ángel s/ incidente de prescripción. E.224 39 del 23 de diciembre del 2004.

21 Todos los integrantes de la Corte Nacional (con algunas variantes argumentales) acataron el pronunciamiento aludido, partiendo de la base de que ella, como parte del Estado, debe cumplir los fallos de la Corte Interamericana, aunque —en este caso- tal actitud perjudique el derecho de defensa en el derecho interno, que tiene raigambre constitucional. 
debe subordinar el contenido de sus decisiones a las de dicho Tribunal internacional...". Consideró que la jurisprudencia de la Corte IDH constituye una imprescindible pauta de interpretación de los deberes y obligaciones derivados de la Convención Americana sobre Derechos Humanos.

Nótese el cambio de lenguaje utilizado por la CSJN cuando en un primer momento se refería a una "guía", y ahora a una imprescindible pauta de interpretación.

Dicho criterio fue ampliamente confirmado y ampliado en el caso Simón, ${ }^{22}$ vinculado con delitos de lesa humanidad, donde el más alto tribunal interno decidió la inconstitucionalidad de dos leyes de impunidad como las llamadas de "obediencia de vida" (Ley 23.521) y "punto final" (Ley 23.492), flexibilizando principios constitucionales como la irretroactividad de la ley penal (en este caso, en perjuicio del reo), cosa juzgada y prescriptibilidad de las acciones. ${ }^{23}$

\section{LA OBLIGATORIEDAD PARA TODOS LOS PODERES PÚBLICOS DE LOS ESTADOS: EFECTOS ERGA OMNES}

La Corte IDH, refiriéndose al Derecho Interno peruano en los casos: Barrios Altos, Tribunal Constitucional de Perú y La Cantuta, puso énfasis en señalar los efectos erga omnes de sus fallos para todo el Derecho Interno de un país, en este caso Perú, ${ }^{24}$ comportándose como un Tribunal Constitucional anulando las leyes de amnistía, con efecto erga omnes y amplificando su doctrina legal, sosteniendo que la vinculatoriedad de sus pronunciamientos no se agota en su parte resolutiva (que vale para el caso particular), sino que se multiplica expansivamente (valga la redundancia) a los fundamentos del fallo, obligando a los tres poderes del Estado para la generalidad de los casos similares.

Este temperamento ha sido receptado también por nuestra CSJN, en los temas vinculados con delitos de lesa humanidad, casos Arancibia Clavel, Simón, René Derecho y Mazzeo, donde se han aplicado a rajatabla dichas pautas jurisdiccionales.

La duda aparece cuando se pretende saber si sus fallos originan una especie de "doctrina legal" de aplicación digamos obligatoria no solo para los delitos de lesa humanidad sino para todos los casos similares, en cualquiera de los países signatarios.

Cuando la CSJN sostiene que los pronunciamientos de la Corte IDH y de la Comisión IDH "deben servir de guía" o que "constituyen una imprescindible pauta de interpretación", está diciendo — desde la perspectiva del derecho interno— que los mismos tienen valor de

22 Corte Suprema Nacional, Simón, Julio H. y otros. Sentencia del 14 de junio de 2005.

23 Ver Calógero Pizzolo. "La validez jurídica en el ordenamiento argentino. El bloque constitucional federal". La Ley (2006).

24 Corte IDH, casos Barrios Altos vs. Perú (Sentencia del 14 de marzo de 2001, serie C, N 75); La Cantuta vs. Perú (cit.) y Tribunal Constitucional vs. Perú (sentencia del 31 de enero de 2001, serie C, No. 71). 
doctrina legal. Y esto ha sido reconocido en el caso Verbitsky, donde la CSJN, siguiendo los pronunciamientos de la Corte IDH, ordenó a un Poder Judicial Estadual adaptar las condiciones carcelarias a los conceptos modernos y a los Poderes Legislativo y Ejecutivo llevar a cabo acciones en tal sentido. ${ }^{25}$

\section{EL CONTROL DE CONVENCIONALIDAD. ACTUACIÓN DE OFICIO}

El término control de convencionalidad fue por primera vez acuñado expresamente por la Corte IDH en su sentencia en el caso Almonacid Arellano vs. Chile. ${ }^{26}$ La Corte IDH consagró que los jueces y tribunales internos no solo están obligados a aplicar las normas vigentes de su ordenamiento jurídico, sino también están sometidos a las disposiciones consagradas en la $\mathrm{CADH}$ y a las interpretaciones que haya hecho la Corte IDH de estas disposiciones.

Dos meses después, en la sentencia dictada en Trabajadores Cesados del Congreso vs. Perú, ${ }^{27}$ la Corte IDH formuló algunas especificaciones y adiciones diciendo que "los órganos del Poder Judicial deben ejercer no solo un control de constitucionalidad, sino también 'de convencionalidad' ex officio entre las normas internas y la Convención Americana". ${ }^{28}$

El mensaje de Trabajadores Cesados del Congreso nos indica que el juez que está habilitado para ejercer el control de constitucionalidad debe asimismo practicar el de convencionalidad. El fallo le reclama, por cierto, tal doble control que debe aplicar incluso de oficio.

Su aplicación en el Derecho Interno argentino ha dado lugar a un interesante diálogo bidireccional con la Corte IDH en el caso Mazzeo, ${ }^{29}$ exponiéndose con claridad el deber de los jueces del Poder Judicial de los Estados de ejercer el "control de convencionalidad" teniendo en cuenta no solamente la $\mathrm{CADH}$ sino también la interpretación que del mismo ha hecho la Corte IDH.

Tiempo después, el máximo tribunal argentino retomó la cuestión en el fallo Videla. ${ }^{30}$ En esta sentencia sostuvo que esta Corte ha precisado que a los efectos de resguardar las obligaciones asumidas por el Estado argentino en el sistema interamericano de protección de los derechos humanos, la jurisprudencia de la Corte IDH es una insoslayable pauta de

25 CSJN, Verbitsky, Horacio. Sentencia del 3 de mayo de 2005.

26 Corte IDH, caso Almonacid Arellano vs. Chile. Excepciones preliminares, fondo, reparaciones y costas. Sentencia del 26 de septiembre de 2006

27 Corte IDH en Trabajadores Cesados del Congreso (Aguado Alfaro y otros) vs. Perú. Sentencia del 24 de noviembre de 2006.

28 Véase Adelina Loiano. "El marco conceptual del control de convencionalidad en algunos fallos de la Corte Suprema Argentina, Arancibia Clavel, Simón, Mazzeo". En El control de convencionalidad, coordinadora Susana Albanese. Buenos Aires: Ediar, 2008, p. 115.

29 CSJN. Sentencia del 13 de julio de 2007.

30 CSJN en Videla, Jorge Rafael y Massera, Emilio Eduardo s/recurso de casación. C.S. V.281. XLV en sentencia del 31 de agosto de 2010. 
interpretación para los poderes constituidos argentinos en el ámbito de su competencia, y que dicho tribunal internacional ha considerado que el Poder Judicial debe ejercer una especie de "control de convencionalidad" entre las normas jurídicas internas que aplican en los casos concretos y la CADH, tarea en la que debe tener en cuenta no solamente el tratado sino también la interpretación que del mismo ha hecho la Corte Interamericana, intérprete última de la Convención.

Así, puede leerse que nuestra CSJN ha convalidado el deber de efectuar — para evitar la responsabilidad internacional del Estado - el control de convencionalidad por parte de los jueces locales, atribuyéndose por consiguiente la facultad institucional de custodio de esta responsabilidad internacional. ${ }^{31}$

El control de convencionalidad desempeñaría un doble papel. Por un lado, un rol represivo que obligaría a los jueces nacionales a inaplicar las normas internas (incluso las constitucionales) opuestas al Pacto de San José (CADH) y a la interpretación que de dicho Pacto ha realizado la Corte IDH. Por el otro, un rol constructivo, que obliga a los jueces a interpretar el Derecho Doméstico de conformidad al Pacto y a su interpretación hecha por la Corte IDH. Es la interpretación "armonizante" o "adaptativa” del Derecho Local con el Pacto y la exégesis dada al Pacto por la Corte IDH. Ello conduce a desechar las interpretaciones del Derecho Nacional opuestas al referido Pacto y/o a la manera en que fue entendido por la Corte IDH. ${ }^{32}$

De lo antedicho se interpreta que la misión fundamental de la Corte IDH está en llevar a cabo una inspección de convencionalidad, la cual consiste en 'comparar' la norma del Derecho Interno en relación a la $\mathrm{CADH}$ y desentrañar si aquélla violenta a esta o no. En el caso de que advierta la violencia, se lo hará saber al país infractor para que modifique los actos ejecutados por cualquiera de sus tres poderes. Ello a fin de evitar que el mismo incurra en responsabilidad estatal (arts. 1.1 y 2 del Pacto aludido).

De todas maneras, resulta necesario remarcar la pauta sobre la importancia de que los jueces locales ejerzan esta tarea para evitar que el pleito llegue a la instancia internacional y la consecuente responsabilidad del Estado, ya que la intervención de la Corte IDH es subsidiaria.

En el ordenamiento jurídico argentino, el control de convencionalidad es asimilable en sus efectos al control de constitucionalidad ceñido al caso concreto, con efectos interpartes. Estos controles tienen en común manejar un mismo argumento: la invalidez de la norma inferior opuesta a la superior.

31 Jorge Alejandro Amaya. Control de Constitucionalidad. Op. cit.

32 Cfr. Néstor P. Sagües. "Dificultades operativas del 'control de convencionalidad' en el sistema interamericano". La Ley (2009-B). 
En el caso de confrontación entre una ley y la Constitución, es evidente la superioridad de la Constitución.

En el supuesto de oposición entre una cláusula de la Constitución y la CADH, el asunto no es tan pacífico y dependerá de la estructura del principio de supremacía.

En el caso argentino se han presentado sintéticamente dos posiciones en torno a la interpretación del artículo 75 inciso 22 de la Constitución que consagró la jerarquía constitucional de los tratados de derechos humanos, sosteniendo que "no derogan artículo alguno de la primera parte de la Constitución y deben entenderse complementarios de los derechos y garantías por ella reconocidos".

Por un lado, está la tesis de los planos intrajerárquicos sostenida por la disidencia de la CSJN en el caso Petric relacionado con el derecho a réplica, la cual entiende que ante una oposición de normas constitucionales y de la $\mathrm{CADH}$ existe una situación jerárquica que privilegia la Constitución; y por otro, la tesis de la complementariedad adoptada como doctrina por la CSJN a partir de los fallos Chocobar ${ }^{33}$ y Monjes, ${ }^{34}$ la cual sostiene que no se hace viable en ninguna hipótesis el descarte e inaplicación de una norma contenida en uno y más instrumentos internacionales de jerarquía constitucional, porque lo que es "complementario" de algo nunca puede dejar se surtir sus efectos "complementarios"

Un tema destacado en el ejercicio del control de convencionalidad por parte de los tribunales internos se ciñe a la llamada doctrina del "margen de apreciación", ${ }^{35}$ que distingue entre un núcleo duro o esencial común para todos y otro más flexible y maleable, que admitiría ciertas modalidades secundarias de extensión y de aplicación, atendiendo las limitaciones, posibilidades y peculiaridades de cada país, su idiosincrasia y experiencias. Esta doctrina fue avalada por la Corte IDH en la opinión consultiva 4/84, referente al trato desigual (más favorable) que dio la Constitución de Costa Rica a los nativos de ciertas naciones de Centroamérica para adquirir la nacionalidad costarricense, cosa que se justificó por los antecedentes históricos y sociológicos comunes que vinculaban a los países del área.

La interrogante se ciñe a si la doctrina de la Corte IDH debe ser efectivizada por los jueces de todos los Estados que han aceptado la competencia de la Corte de una forma inalterable o pueden estos adecuarla a su ordenamiento jurídico interno en virtud de la noción del margen de apreciación.

Considero que la Corte IDH, al sentar las bases del control de convencionalidad, interpretó el instituto con un margen de flexibilidad suficiente para que los Estados apliquen su doctrina

33 CSJN. Sentencia del 27 de diciembre de 1996.

${ }^{34}$ CSJN. Sentencia del 26 de diciembre de 1996.

${ }^{35}$ Néstor Pedro Sagües. La interpretación judicial de la Constitución. 2a ed. Buenos Aires: Lexis Nexis, 2006. 
con una libertad interpretativa y aplicativa sustentada en el principio de proporcionalidad o razonabilidad. Los extremos de esta razonabilidad forman parte del diálogo interjurisdicicional entre la Corte IDH y los máximos tribunales de cada país.

Por último, un tema esencial en el ejercicio del control internacional de la convencionalidad tiene que ver con la cuestión de si una ley incompatible con los derechos humanos reconocidos en la CADH puede justificarse en virtud del principio de las mayorías en una democracia, validando esta ley mediante una decisión soberana.

La Corte IDH en el caso Gelman vs. Uruguay ${ }^{36}$ abordó el tema afirmando que la sola existencia de un régimen democrático no garantiza per se el permanente respeto del Derecho Internacional, incluyendo al Derecho Internacional de los Derechos Humanos; además que, en todo caso, la aprobación popular en una democracia de una ley incompatible con la $\mathrm{CADH}$ no le concede legitimidad ante el Derecho Internacional.

De aquí resulta claro un concepto fundamental que hemos trabajado profundamente: en la configuración del Estado democrático de Derecho, es decir, el Estado constitucional, la regla de la mayoría en la democracia es un principio dual de protección de mayoría y minoría, en la medida en que tanto la actividad de los más como la de los menos se encuentra sometida al respeto y garantía de los derechos humanos consagrados en la Constitución de cada Estado $\mathrm{y}$ en el sistema internacional. ${ }^{37}$

\section{CONCLUSIONES}

Evidentemente, en el mundo globalizado del siglo XXI que transitamos, los tribunales internacionales y los tribunales nacionales forman parte de una "red" jurídica de interpretación de los derechos reconocidos por los instrumentos internacionales y el Derecho Interno. De allí la responsabilidad de todos de contribuir a ese sistema mediante el diálogo entre ellos y el razonamiento responsable de sus decisiones.

Esta responsabilidad en la argumentación de las decisiones judiciales no solo se debe a que en la misma se basa la legitimidad de sus decisiones, sino también porque cada tribunal tiene una responsabilidad — local y mundial — de hacer sus aportes a la construcción de un Derecho judicial universal al que todos los países democráticos aspiramos.

36 Corte IDH, caso Gelman vs. Uruguay. Sentencia del 24 de febrero de 2011.

37 Jorge Alejandro Amaya. "De mayorías y minorías en la democracia". Debates de Actualidad, Asociación Argentina de Derecho Constitucional, 197, año 21 (2006). Ver también: Jorge Alejandro Amaya. "Minorías políticas y procesos mayoritarios" (artículo premiado). Revista de Doctrina del Colegio Público de Abogados de la Capital Federal, 4. 


\section{REFERENCIAS}

- Amaya, Jorge Alejandro. Marburyvs. Madison. Sobreelorigen delcontroldeconstitucionalidad. Bogotá, Colombia: Ediciones Nueva Jurídica, 2012.

- Control de Constitucionalidad. Buenos Aires: Astrea, 2012.

- "De mayorías y minorías en la democracia". Debates de Actualidad, Asociación Argentina de Derecho Constitucional, 197, año 21 (2006).

- "Minorías políticas y procesos mayoritarios" (artículo premiado). Revista de Doctrina del Colegio Público de Abogados de la Capital Federal, 4.

- Ayala Corao, Carlos. "Discurso de incorporación como individuo de número de la Academia de Ciencias Políticas y Sociales de Venezuela". Caracas, Venezuela: Paraninfo del Palacio de las Academias, 8 de marzo de 2012.

- Bidart Campos, Germán. Tratado elemental de Derecho Constitucional Argentino. Tomo I-A. Buenos Aires: Ediar, 2006.

- Hitters, Juan Carlos y Óscar Fappiano. Derecho Internacional de los Derechos Humanos. Buenos Aires: Ediar, 2006.

- Loiano, Adelina. "El marco conceptual del control de convencionalidad en algunos fallos de la Corte Suprema Argentina, Arancibia Clavel, Simón, Mazzeo". En El control de convencionalidad, coordinadora Susana Albanese. Buenos Aires: Ediar, 2008, pp. 114 a 117.

- Pizzolo, Calógero. "La validez jurídica en el ordenamiento argentino. El bloque constitucional federal". La Ley (2006).

- Sagües, Néstor P. Derecho Procesal Constitucional. Logros y obstáculos. Buenos Aires: AdHoc, 2006.

- "Dificultades operativas del 'control de convencionalidad' en el sistema interamericano". La Ley (2009-B).

- La interpretación judicial de la Constitución. 2a ed. Buenos Aires: Lexis Nexis, 2006.

- Vergottini, Giuseppe de. Más allá del diálogo entre tribunales. Madrid: Civitas, 2010.

Recibido: 10/10/14

Aprobado: 28/10/14 